https://doi.org/10.29013/EJLL-19-4-14-17

Kramar Natalia, Ph.D. student, Research and Educational Center for Foreign Languages, National Academy of Sciences of Ukraine, Kyiv, Ukraine E-mail:kra_nat@ukr.net

\title{
A COGNITIVE APPROACH TO RHETORICAL DEVICES IN ACADEMIC DISCOURSE (BASED ON THE FEYNMAN LECTURES ON PHYSICS)
}

\begin{abstract}
The article analyzes rhetorical devices and strategies in one of the most popular science books of all times - the Feynman Lectures on Physics - from the standpoint of cognitive rhetoric as an emerging trend in linguistics. Following the typology of rhetorical devices suggested by R. Harris, we identify key tropes, schemes, chromata and moves in the Lectures as representative of the author's reasoning structures and epistemic beliefs.
\end{abstract}

Keywords: lectures, R. P. Feynman, rhetorical devices, rhetoric, tropes, schemes, chromata, moves.

The rhetorical figures of metaphor and metonymy have come to the forefront of research in cognitive linguistics, being reinterpreted as mental operations that are grounded in human thought rather than language. As rhetoric is further converging with cognitive science, many scholars point out that not only these, but other figures as well are representative of reasoning structures of the speaker. Thus, J. Fahnestock considers rhetorical figures as "epitomes of reasoning structures" [1, 40], emphasizing their salient importance in the development of science, which is no longer viewed as exempt from loaded language and persuasive intentions. The legacy of many prominent scientists is increasingly becoming an object of linguistic research, with a keen eye for their use of rhetorical figures in correlation with the cognitive affinities that undergird them [4].

In this article, we set out to identify and analyze the basic rhetorical figures in the Feynman Lectures on Physics (henceforth FLP) [3] - a series of lectures by famous physicist, Nobel laureate R.P. Feynman, who is well known not only for his contribution to quantum physics, but also for his eccentric and outspoken character. Almost 60 years after their publication, the Lectures still enjoy popularity, which is owed to the simplicity of his style, as well as humor and apt use of rhetorical devices.

The classification of rhetorical figures has been marked with difficulties and contradictions since their earliest treatment in ancient treatises. In the cognitive perspective, one of the most functional typologies was worked out by R. Harris, who is one of the founders and advocates of "cognitive rhetoric" as a new interdisciplinary field of inquiry. Apart from the traditional division into tropes and schemes (as semantic and formal deviations from conventional usage, respectively), he also suggests additional categories of chromata (pragmatic deviations) and moves (a wider and more heterogenerous category embracing different kinds of strategies, such as paralipsis) [5]. A prototypical trope is metaphor - a lexical substitution based on similarity. The primary focus of cognitive linguistics is conceptual metaphor, which is defined as understanding one 
object in terms of another one: it is a certain recurrent model that is grounded in mental processes, in contrast to occasional imaginative metaphors. The conceptual metaphor that is pivotal in Feynman's Lectures (as well as his memoirs) is SCIENCE IS PLAY, which is largely illustrative of the author's personal epistemology. Solving physical problems is often represented in the Lectures as "playing a game":

"Now we play our usual game, we add c; that is to say, we translate the whole curve backward and we find then that it oscillates [...]." [3, I. 34].

Feynman also tends to use the idiom "chid's play" (6 instances) regarding physical problems that can be solved relatively quickly and easily. Furthermore, when leaving some tasks for the students to do on their own (as he was prone to), he specifies that it's for them "to play with", e.g.:

"Now the two sums which appear here we shall leave for the reader to play with and have some fun with" [3, I. 41].

Metaphorical conceptualization of science as play is deeply rooted in the author's epistemic beliefs, as can be seen from his other writings (not pertaining to academic discourse). In his well-known public address "The Value of Science" he points to the so-called "intellectual enjoyment" as one of the main aspects of the value of science, which - for him - is even more important than its practical utility:

"Another value of science is the fun called intellectual enjoyment which some people get from reading and learning and thinking about it, and which others get from working in it" $[2,13]$.

Among deviations from conventional form of utterance - schemes - the most widely featured in the FLP is parallelism, coupled with anaphora or epistrophe. The most expressive cases of parallelism in the FLP are featured in the context of Feynman's emphatic statements about numerous gaps in physical knowledge, which represent one of his most prominent rhetorical "topoi". Consequently, verbs in such parallel anaphoric structures mostly appear in the negative, e.g.:
"We do not know where to look, or what to lookfor, when something is memorized. We do not know what it means, or what change there is in the nervous system, when a fact is learned." [3, III. 7].

"No one has found any machinery behind the law. No one can "explain" any more than we have just "explained." No one will give you any deeper representation of the situation" [3, III. 1].

The rhetorical scheme of climax (alternatively gradatio, incrementum) is another way Feynman frequently uses to underline the miserably limited scope of available scientific knowledge. Likewise, it is mostly formulated in the negative form and centered around epistemic verbs such as to know, to understand, to find out and the like. The word even (associated with the linguistic phenomenon of boosting) is a common lexical marker in such instances of climax:

"We don't know the answer. We don't even know whether we have the "right" problem [... ]" [3, III. 8].

Far from being merely a stylistic embellishment in the text, rhetorical figures of this kind highlight one of the staples of Feynman's scientific outlook namely his conviction that in science "there is an expanding frontier of ignorance" [3, I. 1] and many mysteries of the nature are not just currently unknown, but potentially unknowable. At the same time, in the context of the given discourse they are an effective persuasive instrument, helping the lecturer to arouse and maintain the students' interest, while also guarding them from scientific triumphalism.

Among rhetorical chromata - deviations from conventional intentions associated with a certain form of utterances - the most widely represented in the FLP are rhetorical and hypophorical questions, which are aimed at making a statement more emphatic, not at eliciting information (as real questions are). Most of Feynman's rhetorical questions in the FLP are essentially philosophical as they convey the author's reflections on the nature of human knowledge and its limits:

"Doctors always tell us what the young child "feels," but how do they know what a child feels at the age of one?" [3, I. 36]. 
"The test of science is its ability to predict. Had you never visited the earth, could you predict the thunderstorms, the volcanos, the ocean waves, the auroras, and the colorful sunset?" [3, II. 41].

The basic implication of such questions is that science has not really proceeded too far in grasping the intricate complexity of the universe and the human mind itself. This implication is expressed yet more emphatically in a special type of rhetorical questions that is characteristic of Feynman's discourse - those with no answers known neither to the lecturer nor to the students (they are sometimes labeled with the rhetorical term "conundrum"). Such questions are frequently followed by the statements like "nobody knows" or "we do not know", which belong to FLP's key phrases:

"The question is, of course, is it going to be possible to amalgamate everything, and merely discover that this world represents different aspects of one thing? Nobody knows" [3, I. 2].

"Why does it keep on coasting? We do not know, but that is the way it is" [3, I. 7].

In the last example, Feynman's rhetorical question is related to the issue of inertia, whose machinery - as he wants to make clear - has not been fully explained by scientists since it was discovered by Galileo, despite all the impressive advances in Physics, including the discovery of relativity theory and the development of quantum mechanics. While other scientists may be satisfied by simply stating and describing the law, Feynman goes much deeply in his inquiry, asking questions about the underlying mechanism of the fundamental laws of nature, encouraging his students to be as incessantly curious as he is. At the same time, Feynman's tendency to pose unanswerable questions and admit the impotency of science in many issues demonstrates that he is not afraid to come across as incompetent or having no suggestions of his own. He does not view ignorance as a problem for science to be ashamed of: contrariwise, it is a natural state for science since the area of the unknown only grows larger with each discovery.
Rhetorical moves - the last category in the typology of rhetorical devices by R. Harris - can be defined as different kinds of strategic manouvres mostly associated with the discourse level. The device of this kind that Feynman resorts to most often is procatalepsis - anticipation of future reaction of the audience to the propositional information and refutation of potential counterarguments. The author frequently addresses the audience directly with the phrases like you may/might say, you may/might think, you may/might be wondering, you may object etc. to recognize the doubts and objections the students might have in response to his statements, which he immediately refutes or settles, e.g.:

"You may think: "That's ridiculous; metals are strong." Not so, a single crystal of a metal can be distorted very easily" [3, III. 30].

Remarkably, Feynman not only tends to anticipate the rational responses of the audience (thoughts, objections, doubts), but he also considerately addresses the emotions the lecture material might evoke, particularly the negative ones. This seems to be a specific feature of Feynman's lecture discourse. Thus, he often comforts his students and settles their confusion when information gets too complicated to be understood right away, e.g.:

"You may be worried that what we are saying can only be true for some "special" $z$-axis. But that is not so" [3, II. 34].

"As we go along, the precision of the description will increase, so don't get nervous that we seem to be picking things out of the air" [3, III. 7].

In our view, Feynman's broad use of procatalepsis implies, primarily, the sincere attention and care that he had for the students in trying to facilitate their learning process and organize his discourse in the most efficient way. But at the same time, it serves as a hedging device intended for the author to safeguard himself against criticism. Feynman's precaution is also evident in his prolific use of adverbs and adverbials of probability (like "maybe", "perhaps", "to some extent"), which often modify his statements 
about quantum mechanics as a novel area of physics dominated by uncertainty. The author's striving to foresee the questions and opposing thoughts of the audience wherever possible communicates a strong effect of dialogicity to his lecturing style and helps him establish close rapport with the students.

In the overall, apart from serving the persuasive purpose, rhetorical devices in academic writing and speech can also be approached from cogni- tive perspective as verbal signifiers of a scientist's modes of reasoning and epistemic beliefs. Thus, the most common rhetorical means in the Feynman Lectures on Physics are representative of the author's view of science as being a source of pleasure (with its practical utility being secondary), as well as his emphasis on the limited nature of human mind and the many mysteries of the universe that are yet to be solved.

\section{References:}

1. Fahnestock J. Rhetorical Figures in Science. - New York: Oxford UP. 1999.

2. Feynman R. P. The Value of Science. Engineering and Science, 19(3), 1955.- P. 13-15.

3. Feynman R. P., Leighton R., \& Sands M. (2013, first published in 1964). The Feynman Lectures on Physics. The Feynman Lectures Website. Retrieved October 10, 2019. From: URL:http://www.feynmanlectures.caltech.edu

4. Harris R.A. (2013). The Rhetoric of Science Meets the Science of Rhetoric. Poroi 9 (1). Retrieved October 10, 2019. From URL:https://ir.uiowa.edu/poroi/vol9/iss1/8

5. Harris R. A. The Fourth Master Trope, Antithesis. Advances in the History of Rhetoric, 22 (1), 2019.P. 1-26. 